\begin{tabular}{|l|ccc|}
\hline & PORT-SAID ENGINEERING RESEARCH JOURNAL \\
\hline
\end{tabular}

\title{
Effect of Mass Formation on Indoor Thermal Performance in the Arab Region
}

\author{
Osama Mahmoud Abo EL Einen ${ }^{1}$, Merhan Mohamed Shahda ${ }^{2}$ and Rasha Adel Ali ${ }^{3}$
}

\begin{abstract}
:
The global energy demand has increased, which led to a severe shortage of energy sources in the world. Buildings consume alone about $40 \%$ of total energy production. This is mainly due to the lack of consideration of climatic and environmental factors in the early steps of building design. So we have many buildings with low thermal performance.

In an attempt to find ways to increase the thermal performance of the building, this paper focuses on the study of the relationship between the thermal performance of the building and the most important element in the design of the building is the building shape. The paper focused on the Arab world's climate, especially in hot climates (hot-dry, hothumid).

The simulation was conducted using Design Builder program in two cities, in Jeddah in Saudi Arabia (which represents a hot-dry climate) and the other city is Port Said in Egypt (which represents a hot-humid climate). Several shapes were compared and these shapes are circle, square, rectangle by different ratios, L shape, U shape and courtyard. The results varied in each climate:

In hot- dry climate: 1) The courtyard shape helped in saving 53\% of the energy. 2) By directing the building to the north or south, saves $10 \%$ of the energy. 3) When the percentage of openings $10 \%$ provided $44 \%$ of the energy.

In hot-humid climate: 1) The square shape has the best thermal performance since it saves about $46.5 \%$ of the energy. 2) The building which directed to the north provides about $14 \%$ of the energy. 3) The percentage of openings in the building when $10 \%$ provides $52.8 \%$ of energy.
\end{abstract}

KEYWORDS: Building form, Arab Region, hot-dry climate, hot-humid climate, and Thermal performance.

\section{1- INTRODUCTION:}

Climate is one of the most important elements affecting the design of the building. Over the centuries humans have tried to develop ways and means to provide adequate shelter for the surrounding environment to achieve thermal comfort within. He developed a traditional home, which achieved thermal comfort based on natural resources and the primitive strategies of passive solar design $[1,2]$.However, the modern house neglected to take into account climate elements in achieving thermal comfort. Instead, the buildings relied on electrical equipment that uses energy while the world faces a major energy problem. So buildings become the main consumer of energy, especially for cooling. Therefore, the problem of low energy is constantly increasing with this development. So, the climate must be one of the most important design criteria for buildings to achieve the highest degree of internal thermal comfort $[3,4]$.

${ }^{I}$ Associate Professor, Architecture and Urban Planning Department, Faculty of Engineering, Port Said University, Port Said, Egypt, E-mail: aboeinen@hotmail.com

${ }^{2}$ Lecturer, Architecture and Urban Planning Department, Faculty of Engineering, Port Said University, Port Said, Egypt, E-mail: m.shahda@eng.psu.edu.eg

${ }^{3}$ Demonstrator, Architecture and Urban Planning Department, Faculty of Engineering, Port Said University, Port Said, Egypt, E-mail: rasha.adel@eng.psu.edu.eg
The thermal performance of the building refers to the process of modeling energy transfer between the building and its surroundings. For an air-conditioned building, the heating and cooling load is estimated [5, 6].For a non-air-conditioned building, it calculates the temperature change within the building over a specified period of time and helps the designer estimate the duration of the uncomfortable periods. These designed quantities enable design of the building to be effectively identified and help to develop improved designs for energy-saving buildings [7]

Energy consumption in buildings is related to the thermal performance of the building. Heat transfer across building components, from heat gain or loss to internal heat gain and ventilation gain, is one of the most important factors affecting thermal performance [8]. The thermal performance of the building depends on a large number of factors that can be summarized in the figure. 1 $[9,10]$ 


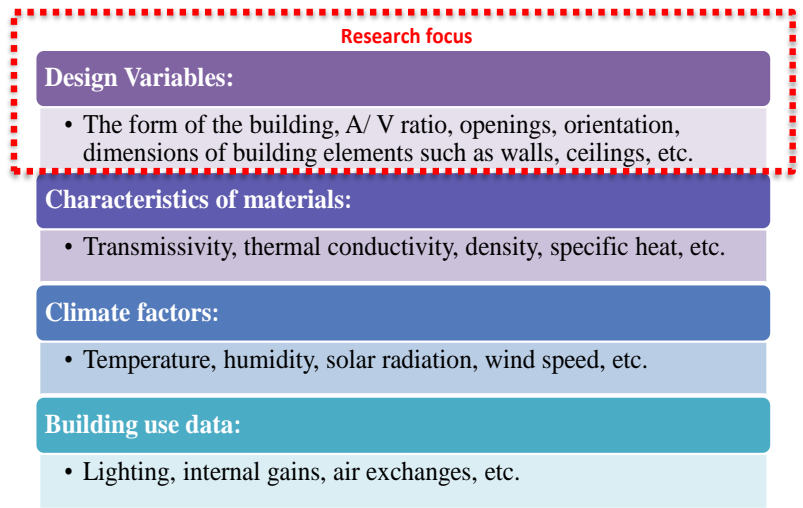

Figure. 1: Factors affecting the thermal performance of buildings.

\section{Design Variables:}

Buildings are the main element responsible for internal thermal conditions and internal climate as they form the main link between the external and internal environment. Therefore, many design variables should be considered and studied, and it can be summarized and summarize its impact on the thermal performance of the following elements [11]:

\section{A) Building form:}

The shape of the building is one of the most important considerations in the step of the building design, because the shape of the building determines the size of the external shell exposed to the external environment, thus affecting the thermal performance of the building [12]. The building shape affects the internal climate of the building, and also affects the total loss and gain of the heat through the building's casing [13].

\section{B) Orientation:}

The orientation of the building has a great role in providing the thermal comfort of the building. The orientation must be determined along with the shape of the building early in the design process [14]. The best orientation of the building requires obtaining the maximum solar radiation in the winter and the minimum in the summer [15].

\section{C) Openings:}

The size, shape and location of the window depend on prevailing local climatic conditions, but the openings represent a weak point in the outer shell of the building where the building acquires the highest radiation intensity through the openings. Thus, the treatment of the openings has an effective role in reducing the thermal loads within the building areas [16].

The research aims to measure the effect of the shape and orientation of the building and the ratio of the openings of it on the thermal performance of the building, by focusing on the hot climates (hot-dry, hothumid) and to elicitation the best formations for each climate using the DESIGN BUILDER simulation program.

\section{METHODOLOGY:}

The constructor simulation program "The Design Builder" was used to examine the optimal building model in reducing the loads and energy consumed to achieve thermal comfort inside the building, The program uses the Energy Plus simulation engine to create performance data. It is an easy-to-use modeling environment where you can work with virtual building models. It provides a range of environmental performance data such as: annual power consumption, extreme summer temperatures and sizes of HVAC components [17]

First, many assumptions about internal and external conditions are defined for equal analysis of alternatives. The indoor rest temperature is set at $26^{\circ} \mathrm{C}$ for summer period and $21^{\circ} \mathrm{C}$ for winter period. The climatic data for the selected countries is obtained through the climate files in the program [18].

I $\mathrm{n}$ the search for the optimal shape of the building in both hot-dry and hot-humid climate, which contains maximum thermal comfort, containing less cooling /heating loads and less energy consumption, A comparison was made between the building forms in Jeddah in Saudi Arabia, which represent the hot-dry climate, and Port Said city in Egypt, which represents the hot-humid climate. Figure. 2 shows a map of the temperature of each country.

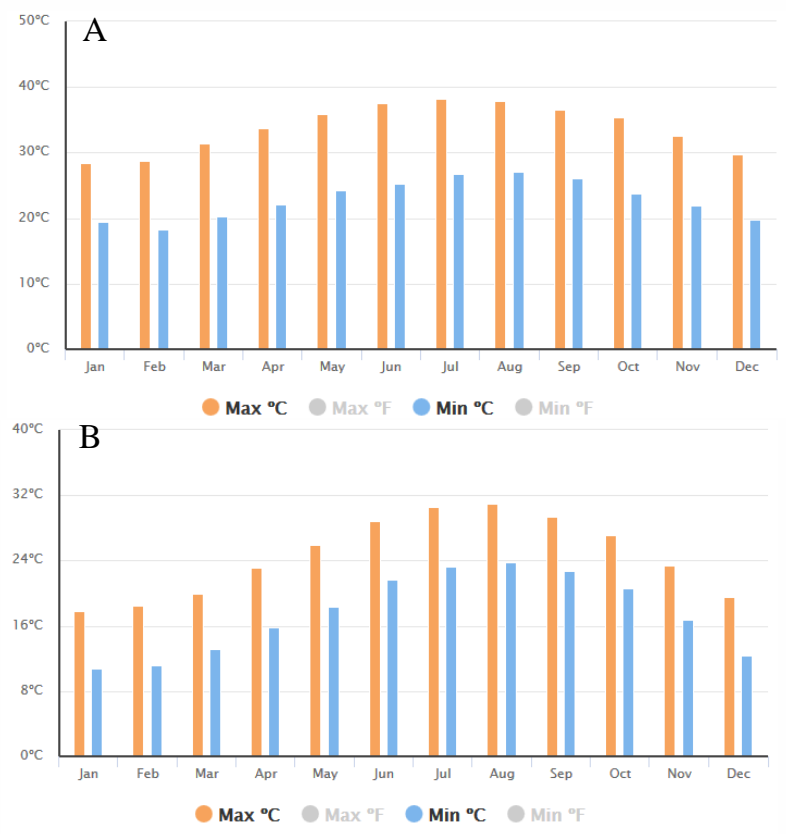

Figure. 2: A) average temperature in Jeddah, B) average temperature in Port Said.

Source: (https://www.weather2visit.com/)

The analysis was performed on eight building forms as shown in Figure. 3, in order are the circle, the square, the rectangle in ratios 1:2, 1: 3 and 1: 4 ratio of width to length, L shape, U shape, and courtyard. The study was conducted by comparing the thermal loads and energy consumption.

After selecting the best shape for each climate, change in the orientation of the building to determine the optimal orientation in each climate, and after the knowledge of 
the optimal form as well as the optimal orientation was the change in the ratio of openings to determine the proportion of openings ratio to each shape in each climate to conclude the effect of both form and orientation and openings on thermal performance of the building.

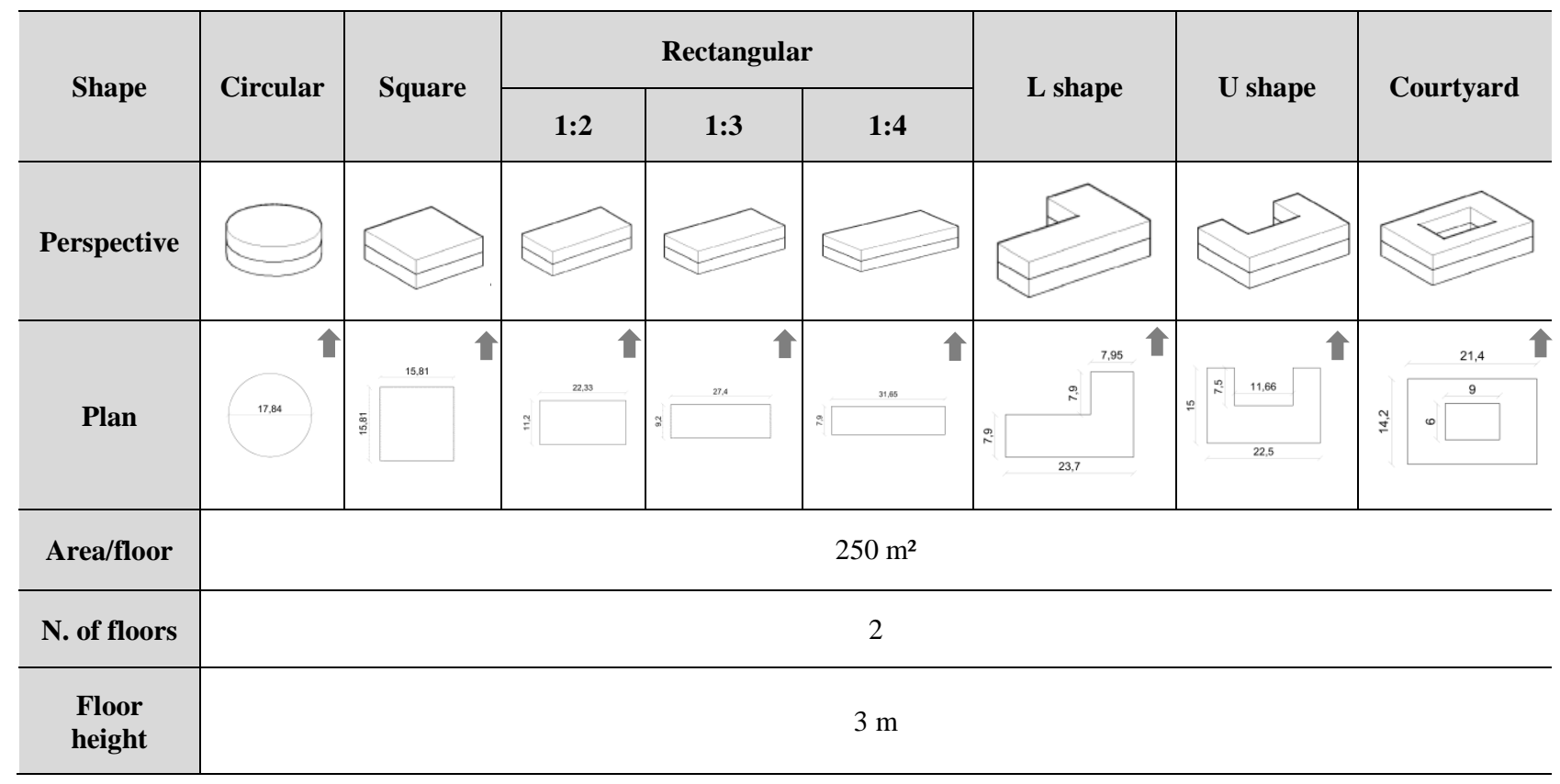

Figure. 3: The tested building forms design parameters.

\section{Parameters:}

A two-storey building was designed, each floor is 250 $\mathrm{m}^{2}$ and the height of each floor is $3 \mathrm{~m}$. The ratio of the openings in all shapes was fixed $10 \%$. The parameters are installed in each building. Table 1 shows the building parameters used in the simulation program for all tested models.
It should be noted that these parameters have been installed in all models, and the selection of layers with specific thicknesses and materials has been taken into consideration for low thermal transmittance.

Table 1: Simulation parameters for building forms.

\begin{tabular}{|c|c|c|c|c|}
\hline Building component & Thickness & \multicolumn{2}{|l|}{ Material } & U-value $\left[\mathbf{w} / \mathbf{m}^{2} \mathbf{k}\right]$ \\
\hline External walls & $\begin{array}{l}2 \mathrm{~cm} \\
37 \mathrm{~cm} \\
2 \mathrm{~cm}\end{array}$ & \multicolumn{2}{|c|}{$\begin{array}{l}\text { Cement/plaster/mortar } \\
\text { Concrete block } \\
\text { Cement/plaster/mortar }\end{array}$} & 0.460 \\
\hline Roof & $\begin{array}{l}2 \mathrm{~cm} \\
2 \mathrm{~cm} \\
6 \mathrm{~cm} \\
5 \mathrm{~cm} \\
2 \mathrm{~cm} \\
20 \mathrm{~cm} \\
2 \mathrm{~cm}\end{array}$ & \multicolumn{2}{|c|}{$\begin{array}{c}\text { Concrete tiles } \\
\text { Mortar } \\
\text { Sand and gravel } \\
\text { Foam- polyvinylchloride } \\
\text { Bitumen, felt/ sheet } \\
\text { crete, Reinforced }(2 \% \text { steel }) \\
\text { Cement/plaster/mortar }\end{array}$} & 0.547 \\
\hline Internal slabs & $\begin{array}{l}2 \mathrm{~cm} \\
2 \mathrm{~cm} \\
6 \mathrm{~cm} \\
20 \mathrm{~cm} \\
2 \mathrm{~cm}\end{array}$ & \multicolumn{2}{|c|}{$\begin{array}{c}\text { Ceramic floor tiles } \\
\text { Mortar } \\
\text { Sand and gravel } \\
\text { Concrete roofing slab } \\
\text { Cement/plaster/mortar }\end{array}$} & 0.615 \\
\hline Ground floor & $\begin{array}{l}5 \mathrm{~cm} \\
2 \mathrm{~cm} \\
10 \mathrm{~cm} \\
2.5 \mathrm{~cm} \\
75 \mathrm{~cm}\end{array}$ & \multicolumn{2}{|c|}{$\begin{array}{l}\text { Flooring screed } \\
\text { EPS } \\
\text { Cast concrete } \\
\text { Brick slips } \\
\text { Clay under floor }\end{array}$} & 0.273 \\
\hline \multirow{2}{*}{ Window } & \multirow{2}{*}{$\begin{array}{c}3 \mathrm{~mm} \\
13 \mathrm{~mm} \\
3 \mathrm{~mm}\end{array}$} & \multirow{2}{*}{$\begin{array}{l}\text { Generic clear } \\
\text { Air } \\
\text { Generic clear }\end{array}$} & Ratio & \multirow{2}{*}{1.960} \\
\hline & & & $10 \%$ & \\
\hline
\end{tabular}




\section{RESULTS:}

The results showed that the effect of building shape on the thermal loads, energy consumption and thermal performance of the building varies according to the climate chosen.

\subsection{For hot-dry climate:}

\section{A) Building shape:}

The results shown in Figure. 4 indicate that the cooling loads increased by $47 \%$, while the heating load increased three times from the change of the building shape from the circle to the courtyard.

The same trend for the increase can be seen in total cooling and heating energy consumed as shown in Figure. 5, as the cooling energy increased by the same increase of cooling loads of $46 \%$ and the heating energy also increased by three times from the change of the building shape from the circle to the courtyard.

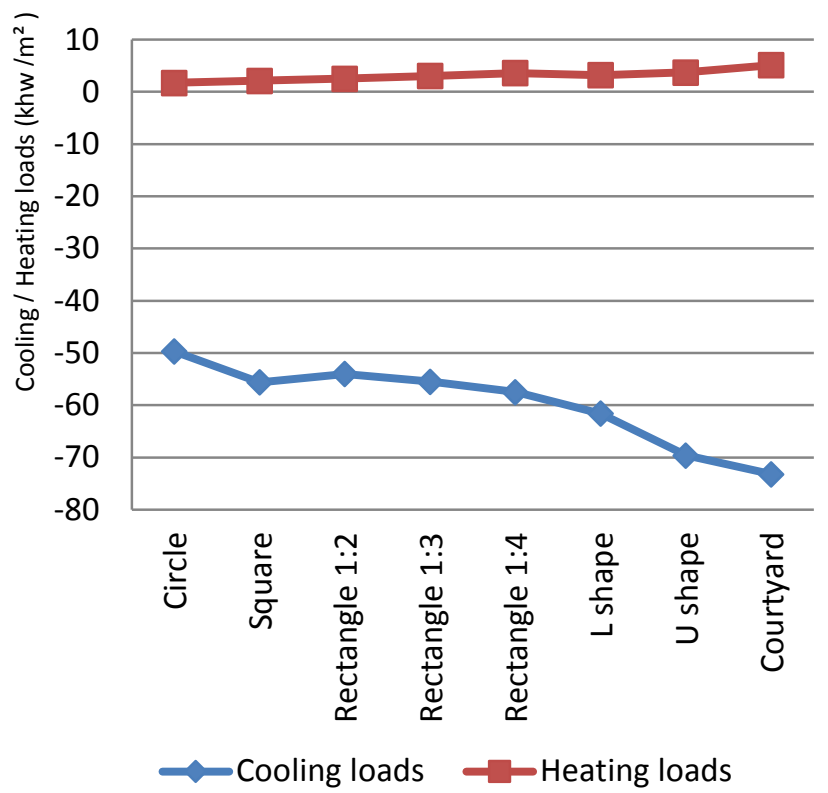

Figure. 4: Annually cooling / Heating loads for tested forms.

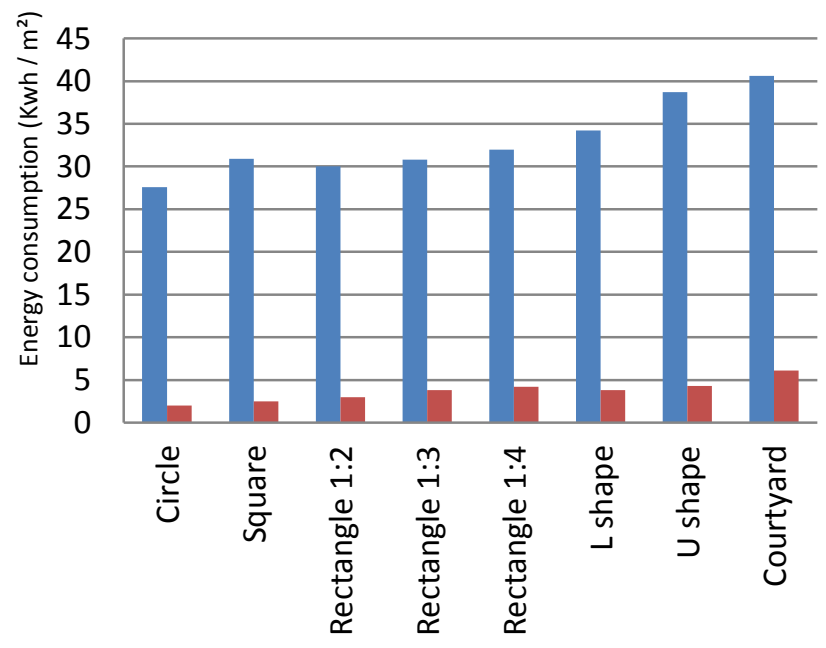

Cooling (Electricity) Heating (Electricity)

Figure. 5: Annually energy consumption for tested forms.
For the rectangular shape, we notice a change in its effect with a change in its ratio. When it was 1: 1 (square), the load and energy required were $12 \%$ higher than the circular shape. When the width to length ratio increased to $1: 2$, the loads and energy required significantly decreased from the square shape, this means that the rectangular shape has a ratio of $1: 2$ is better than the square because by increasing the ratio the length of the northern facade increases. As the ratio increases to $1: 3$ and 1:4, the loads and energy needed increased again from the square shape. This may be due to the fact that by increasing the width to length ratio, this increases the length of the southern façade, this means that the building is more exposed to sunlight in the afternoon, which increases the heat loads on the building and the energy needed to get rid of those heat loads. We conclude from this that the best proportion of rectangular shape in the ratio of length to width 1: 2 . We conclude from this that the best proportion of the rectangular shape when the ratio of width to length 1:2.

The previous results showed that the courtyard shape was not the best solution for the buildings in the hot-dry climate, where the cooling loads and energy required in the summer increased by $47 \%$ compared to the circular shape, and had the lowest performance in all tested forms, while it was commonly thought to be the most appropriate forms in the hot-dry climate, the next step in the search is to look for the reason behind it.

- Why was it thought to be the best forms of dry hot climate?

- Should it have specific design dimensions and

Standards to be the ideal solution for buildings?

- What is the appropriate yard ratio to achieve the highest performance?

In order to know this, there was a change in the ratios of the yard to find out the relationship between its proportions and its thermal performance.

In the same building area of the previous models (the occupied area $=250 \mathrm{~m}^{2}$ ), and the same height of meters $(\mathrm{h}=6 \mathrm{~m})$, the central courtyard plan was chosen from among four types of plans that can be seen in general as shown in Figure. 6. The models chosen to change the width of the courtyard for its fixed height from the first models were models $\mathrm{W}=(\mathrm{H}, 1.5 \mathrm{H}$, and $2 \mathrm{H})$.

\begin{tabular}{|c|c|c|c|c|}
\hline Shape & $W=H$ & $\mathrm{~W}=1.5 \mathrm{H}$ & & $W=2 \quad H$ \\
\hline \multicolumn{5}{|l|}{ Perspective } \\
\hline & 18.91 & 21,4 & & 25,4 \\
\hline Plan & 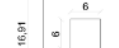 & 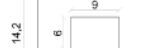 & 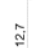 & 。 \\
\hline $\begin{array}{c}\text { Area of } \\
\text { courtyard }\end{array}$ & $36 \mathrm{~m}^{2}$ & $54 \mathrm{~m}^{2}$ & & $72 \mathrm{~m}^{2}$ \\
\hline Exterior area & $286 \mathrm{~m}^{2}$ & $304 \mathrm{~m}^{2}$ & & $322 \mathrm{~m}^{2}$ \\
\hline Occupied area & \multicolumn{4}{|c|}{$250 \mathrm{~m}^{2}$} \\
\hline
\end{tabular}
of court shape. 
Figures. 7, 8 show the effect of changing the courtyard ratios (width to height) on the cooling/ heating loads and the energy consumed throughout the year. When the height of the courtyard is equal to its width, it is given better results as it has less cooling/ heating loads and less energy consumption. The higher the width of the building, the higher the loads and the energy consumed. We also note that the performance of this courtyard is better than the courtyard which was compared to the previous basic shapes in the figure. 3, we conclude from this point that the best performances of the courtyard when the width is equal to the height and less performance the greater the width of the height.

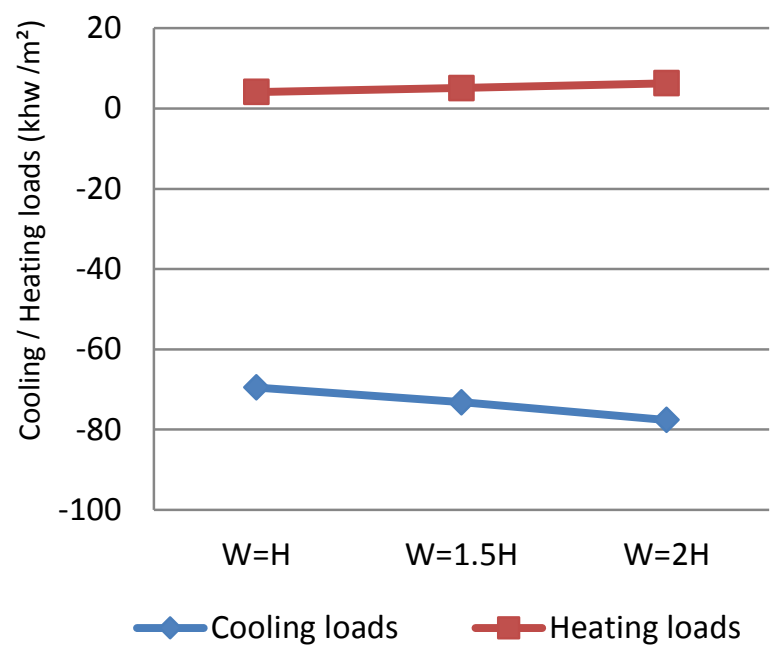

Figure. 7: Annually cooling/ heating loads for different ratios of court shape.

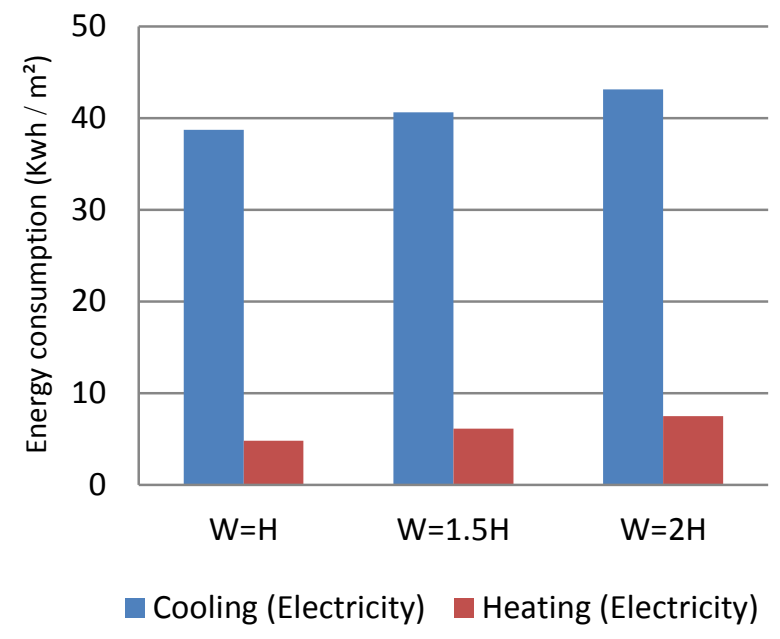

Figure. 8: Annually energy consumption for different ratios of court shape.

However, by comparing this courtyard shape to the rest shapes results in Figures. $(4,5)$, the form of the courtyard still has a higher thermal load and greater energy consumption than other forms and has not yet reached the best thermal performance. So, the second step was to reduce external openings and increase openings in the court and raise its level to help in exiting the hot air during the day while allowing for cold air to enter the spaces at night, and the court is provided with arcades to help in shading, those arcades with full court height and also used as covered corridors. Figures. (9, 10) show the results after this modification in the courtyard. We observe a significant decrease in the cooling/heating loads and energy consumed, to the degree that the loads and energy decreased from the circular shape. The figures show the comparison between the results of both the circular shape and the shape of the tested courtyard in the first step and the courtyard after making modifications to it (in terms of changing the ratio to $1: 1$ and the last modifications in the openings and arcades) and differences are clear

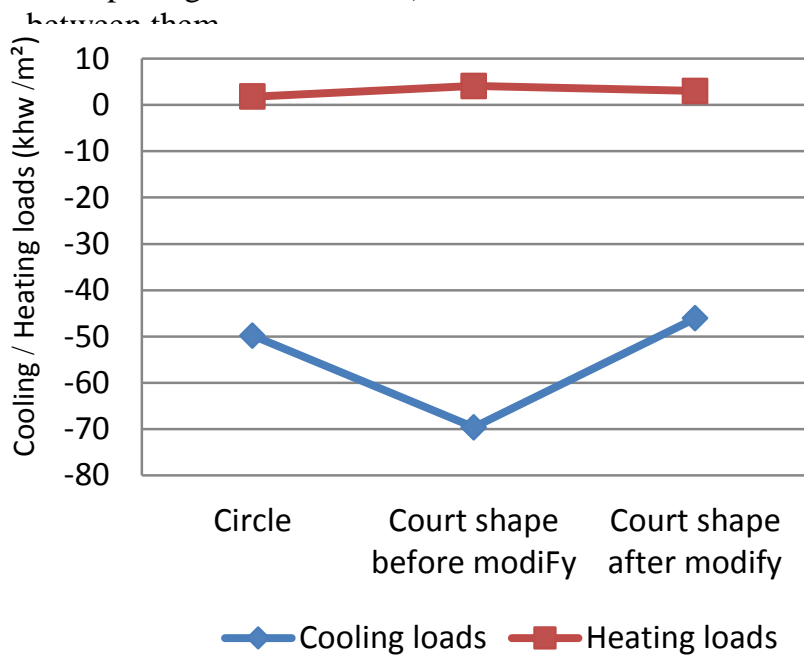

Figure. 9: Annually cooling/ heating loads for circle and court shape.

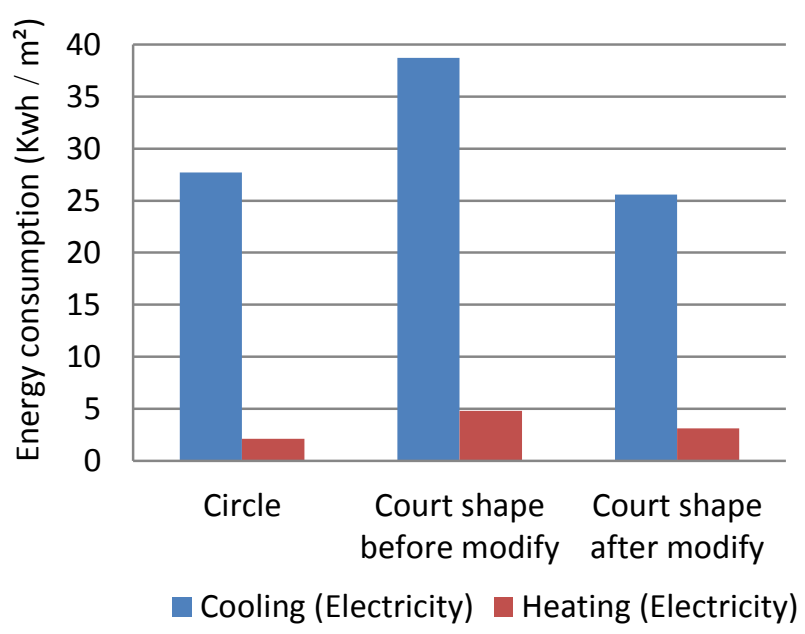

Figure. 10: Annually energy consumption for circle and court shape.

\section{B) Building Orientation:}

After knowing the optimal building shape for the hotdry climate, which helps to raise the performance of the building in terms of reducing the thermal loads on it, here comes an important step in determining the most appropriate orientation for buildings in the hot-dry climate, without this step may be a step to determine the 
appropriate shape of the building is not effective and does not give the desired results, after determining the appropriate shape of the building if placed in the wrong orientation does not produce effective results in reducing the thermal loads, but on the contrary can increase the thermal loads and consume more electrical energy to offset those loads of heat.

For this purpose, a change of orientation was performed on each of the previous models in the four main directions: North, East, South and West. But results were in orientations where there was a change from other orientations. As the circle and square shapes are symmetrical in all orientations, so the results of the north were displayed only to represent all orientations. When there are no differences between north and south or east and west, the results of the north direction represent also the southern direction, and the results of the eastern orientation represent the western orientation (for both the rectangle and the courtyard). However, if there are differences of form in the four orientations, the results are presented for all orientations as shown in Figure. 11.

Figure. 11 shows the amount of electrical energy consumed to compensate the thermal loads on the building (cooling or heating) throughout the year, it is clear from the figure that for the rectangular form of all tested ratios, the best orientation when directing the large side to the north (or south), it can save the energy annually by up to $10 \%$, and should not be directed to the east (or west). For the L shape, by directing the open part to the north or south, it can save energy annually by up to $7 \%$. For the $U$ shape, there are no big differences in the four orientations, where the difference is too small up to $0.2 \%$, can be ignored. For the courtyard shape, also the best orientation is to direct the larger side if, it is rectangular, to the north (or south) it reduces energy by up to $5 \%$.

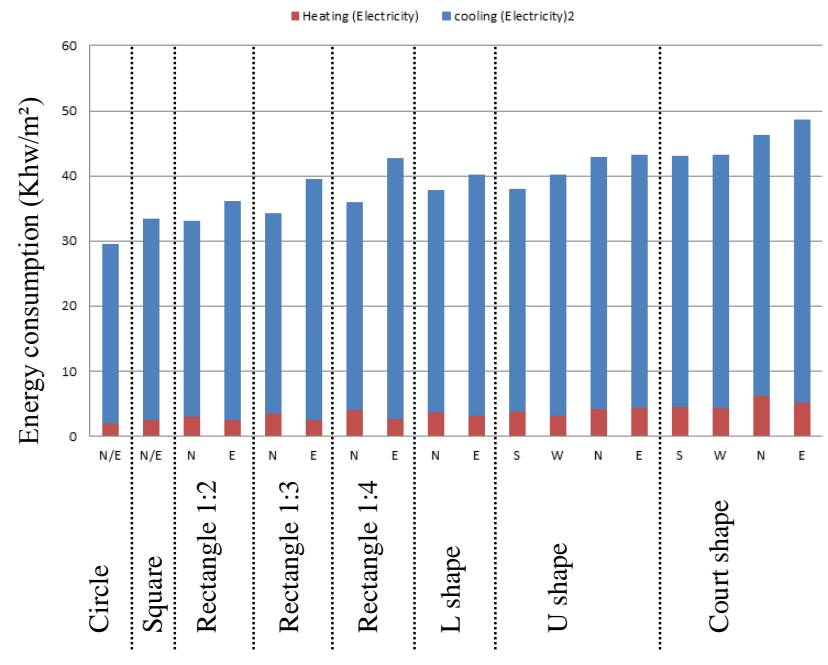

Figure. 11: Annually energy consumption for tested forms in different orientation.

\section{C) Openings:}

The percentage of openings in the building plays a big role in the thermal loads on the building, thus increasing or decreasing the performance of the building. Therefore, determining the appropriate proportion of the openings of the buildings in each climate, especially the hot-dry climate, is a major step in the passive design of the building.

Changes were made in the percentage of openings of the tested models shown in the figure. 12. Comparison of ratios $10 \%$ and $20 \%$ of openings in the same building conditions was made in the first comparison. The figure shows the large effect of the ratio of the openings on the energy consumed, whether for cooling or heating. The energy consumed increased significantly when the openings increased from $10 \%$ to $20 \%$ in all models. The rate of increase in energy between the two ratios reached to $44 \%$, which indicates that, the higher the percentage of openings in the building in the hot-dry climate, the higher the thermal loads on it and the lower the thermal efficiency and the more energy consumed to compensate those loads, it is preferred to be the proportion of openings only $10 \%$ and not exceed this percentage.

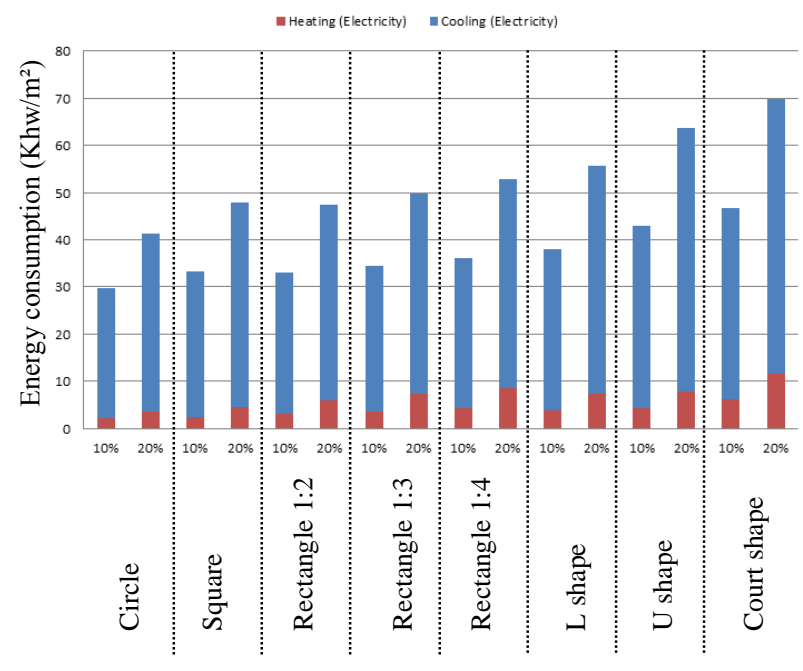

Figure. 12: Annually energy consumption for tested forms with different window ratio.

\subsection{For hot-humid climate:}

By applying the same basic steps as the previous one in the climate of Port Said city in Egypt, which is characterized by hot-humid climate, comparing the same eight shapes and the same criteria.

\section{A) Building form:}

The results shown in Figure 13 show that the cooling and heating loads differed completely from the hot-dry climate, while the circular shape in the hot-dry climate was less thermal loads, followed by the rectangle with ratio $1: 2$, the results here show that the square shape is the best form as it reduced thermal loads by up to $46.5 \%$, followed by rectangle with a ratio of $1: 3$, followed by the rectangle with a ratio $1: 2$, then the circle shape, and the more thermal load forms is the courtyard shape.

Figure 14 shows the same increase in energy consumed annually in cooling and heating, as the energy consumption for heating increased from $7.5 \mathrm{Khw} / \mathrm{m}^{2}$ to $11.25 \mathrm{Khw} / \mathrm{m}^{2}$ from the square shape to courtyard. As for the energy needed for cooling increased from 11.4 $\mathrm{Khw} / \mathrm{m}^{2}$ to $14.2 \mathrm{Khw} / \mathrm{m}^{2}$. 
For the square and rectangle, we note from Figures 13, 14 that the loads and energy consumed in the square are less load and energy consumed, then the ratio increased to $1: 2$, the loads and the energy consumed increased by the square shape. By increasing the ratio to $1: 3$, the loads and the energy were reduced again to the ratio to the square shape, increasing the ratio to $1: 4$ increased loads and energy again, this shows the significant impact of change in shape ratio on the cooling/heating loads and energy consumption.

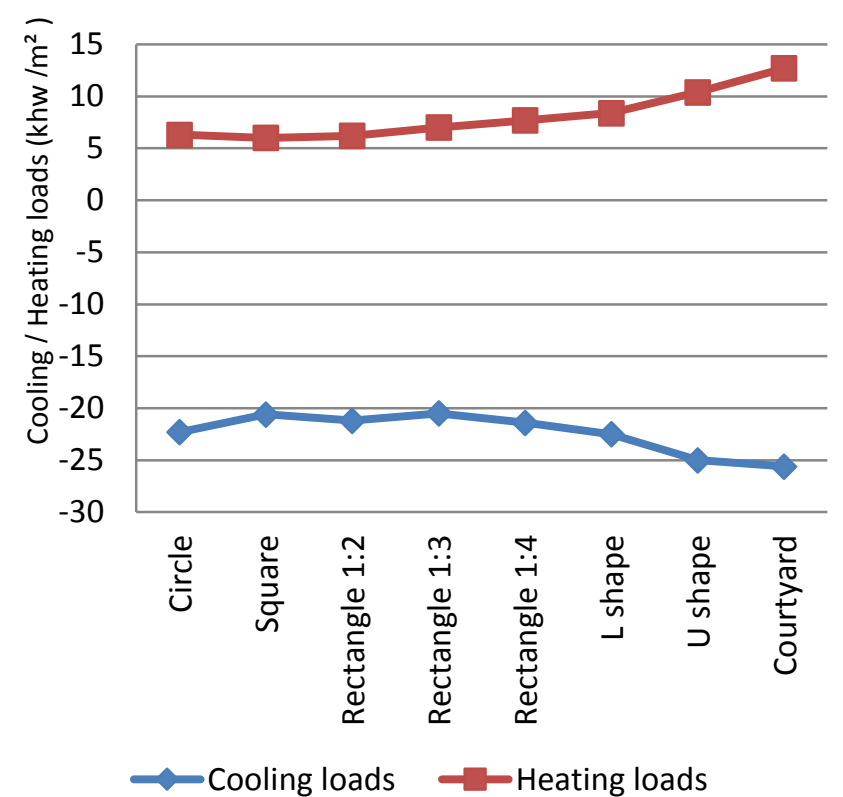

Figure. 13: Annually cooling/heating loads for tested forms.

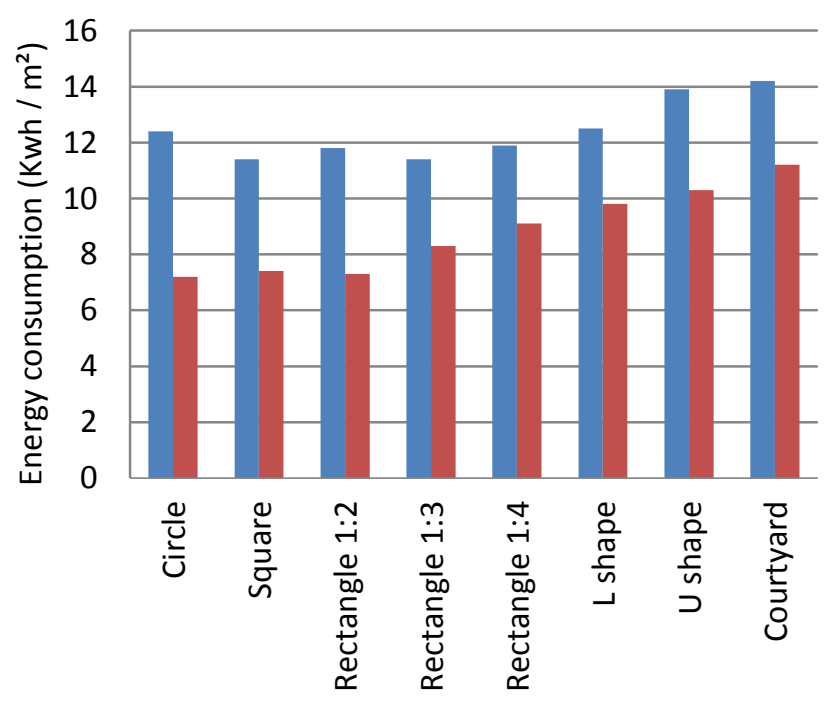

Cooling (Electricity) Heating (Electricity)

Figure. 14: Annually energy consumption for tested forms.

\section{B) Building Orientation:}

Figure. 15 shows the results of the amount of energy consumed for the eight shapes in the different orientations that have an impact on the change of result. It is also clear that the best orientation of the building is the northern direction. For the rectangular shape, orientation played a major role in reducing thermal loads and reducing energy consumption. For a rectangle with a ratio of $1: 2$, the direction of the larger side of the building to the north or south led to a reduction of nearly $10 \%$ of the total energy if directed to the east or west. The rectangle with a ratio of $1: 3$ was saved nearly $17.8 \%$ of the total energy. The rectangle with a ratio of 1:4 was saved nearly $23.1 \%$ of the total energy. As for the $\mathrm{L}$ shape building, the direction of the open part to the north or south reduced the consumption of neat to $7 \%$ of energy, while in the $U$ shape building, there were no clear differences between the directions except the direction in which the open part directed to the north, which reduced the consumption of nearly $7.1 \%$ of the energy. Finally for a courtyard-shaped building, as shown in the figure the difference is clear which is near to $21 \%$ of the total energy consumption.

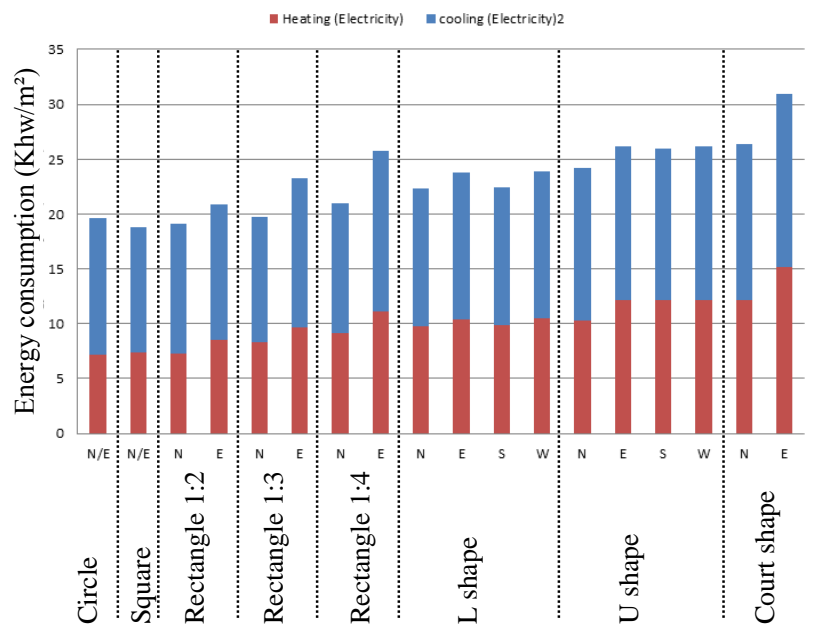

Figure. 15: Annually energy consumption for tested forms in different orientation.

\section{C) Openings:}

Comparison of tested models with window ratio changes from $10 \%$ to $20 \%$, Figure. 16 shows that the energy consumed in some forms increased by about $52.8 \%$, but it is noted here that not only the cooling energy which increased but also the increase in heating energy also by a large percentage. 


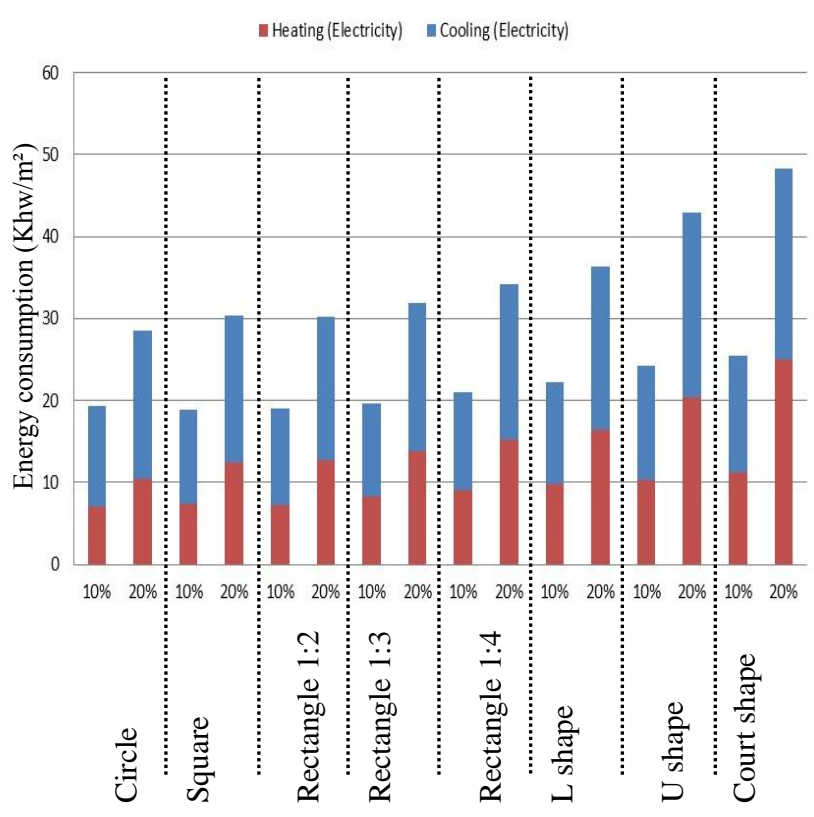

Figure. 16: Annually energy consumption for tested forms with different window ratio.

\section{CONCLUSION:}

From the previous results, there is an important relationship can be concluded between the mass formation of the building, including the form of the building and orientation and the ratios of openings, and thermal performance of the building, and thus reduce or increase the thermal loads on the building and energy consumed.

\begin{tabular}{|c|c|}
\hline \multirow[b]{2}{*}{ Form } & Hot-Dry climate \\
\hline & $\begin{array}{l}\text { The courtyard has an equal height to } \\
\text { width, and has arcades in the court } \\
\text { with raised openings in the court is the } \\
\text { best shape, where it helped in saving } \\
53 \% \text { of the energy. } \\
\text { Comes after the courtyard, the circle } \\
\text { shape where it helped save } 46 \% \text { of the } \\
\text { energy, then the rectangle by ratio } 1: 2 \text {. }\end{array}$ \\
\hline \multirow{2}{*}{$\begin{array}{l}\text { Orientation } \\
\text { Openings }\end{array}$} & $\begin{array}{l}\text { The best orientation for all models is } \\
\text { the longer rib orientation to the north. }\end{array}$ \\
\hline & $\begin{array}{l}\text { The } 10 \% \text { opening ratio helped save } \\
44 \% \text { of the energy }\end{array}$ \\
\hline \multirow[b]{2}{*}{ Form } & Hot-Humid climate \\
\hline & $\begin{array}{l}\text { The square shape was the best } \\
\text { performance for the buildings in this } \\
\text { climate, } 46.5 \% \text { of the energy was } \\
\text { provided. } \\
\text { The best shape after the square was the } \\
\text { rectangle with a ratio of } 1: 3 \text {, followed } \\
\text { by the rectangle with a ratio } 1: 2 \text {. }\end{array}$ \\
\hline Orientation & $\begin{array}{l}\text { Directing the building to the north has } \\
\text { saved about } 14 \% \text { of the energy. }\end{array}$ \\
\hline Openings & The best ratio for openings is $10 \%$. \\
\hline
\end{tabular}

\section{REFERENCES:}

1. Olgyay, V., Design with Climate: Bioclimatic Approach to Architectural Regionalism-New and expanded Edition. 2015: Princeton university press.

2. Bano, F. and V. Sehgal, Evaluation of energyefficient design strategies: Comparison of the thermal performance of energy-efficient office buildings in composite climate, India. Solar Energy, 2018. 176: p. 506-519.

3. Yılmaz, Z., Evaluation of energy efficient design strategies for different climatic zones: Comparison of thermal performance of buildings in temperate-humid and hot-dry climate. Energy and Buildings, 2007. 39(3): p. 306-316.

4. Zhai, Z.J. and J.M. Helman, Implications of climate changes to building energy and design. Sustainable Cities and Society, 2019. 44: p. 511-519.

5. Albatayneh, A., et al., Assessment of the Thermal Performance of Complete Buildings Using Adaptive Thermal Comfort. Procedia - Social and Behavioral Sciences, 2016. 216: p. 655-661.

6. Alalouch, C., et al., Energy saving potential for residential buildings in hot climates: The case of Oman. Sustainable Cities and Society, 2019. 46: p. 101442.

7. Nayak, J. and J. Prajapati, Handbook on energy conscious buildings. Prepared under the interactive R \& D project, 2006(3/4): p. 03.

8. Ghisi, E. and R.F. Massignani, Thermal performance of bedrooms in a multi-storey residential building in southern Brazil. Building and Environment, 2007. 42(2): p. 730-742.

9. Lee, J., et al., Thermal performance evaluation of low-income buildings based on indoor temperature performance. Applied Energy, 2018. 221: p. 425-436.

10. Shi, L., et al., Optimizing the thermal performance of building envelopes for energy saving in underground office buildings in various climates of China. Tunnelling and Underground Space Technology, 2018. 77: p. 26-35.

11. Abed, H.M.H., Effect of Building Form on the Thermal Performance of Residential Complexes in the Mediterranean Climate of the Gaza Strip. 2012, Islamic University of Gaza.

12. Wang, W., H. Rivard, and R. Zmeureanu, Floor shape optimization for green building design. Advanced Engineering Informatics, 2006. 20(4): p. 363-378.

13. Rosenlund, H., Climatic design of buildings using passive techniques. 2000: Lund University, Housing Development and Management.

14. Abanda, F.H. and L. Byers, An investigation of the impact of building orientation on energy consumption in a domestic building using emerging BIM (Building Information Modelling). Energy, 2016. 97: p. 517-527.

15. Bano, F. and M.A. Kamal, Examining the Role of Building Envelope for Energy Efficiency in Office Buildings in India. Architecture Research, 2016. 6(5): p. 107-115 
16. de Castro, L.R., C. Vigneault, and L.A. Cortez, Container opening design for horticultural produce cooling efficiency. Journal of Food Agriculture and Environment, 2004. 2: p. 135-140.

17. ; Available from: https://designbuilder.co.uk/whatsnew-in-v5.

18. Kocagil, İ.E. and G.K. Oral, The effect of solar heat gain on climate responsive courtyard buildings. ITU A|Z, 2016. 13(2): p. 39-46.

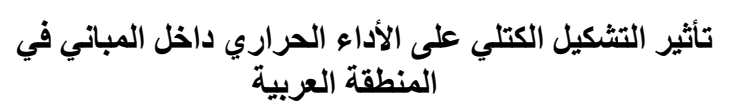

لزيادة الطلب العالمي على الطاقة، أدى ذلك إلى نقص شديد في مصادر

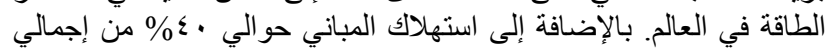

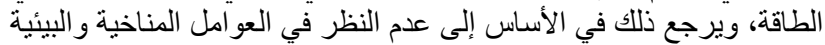

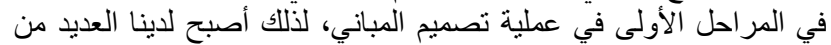

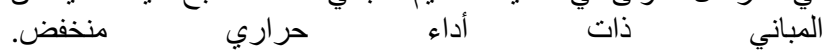

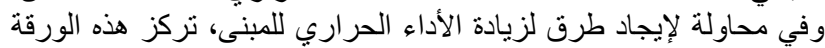

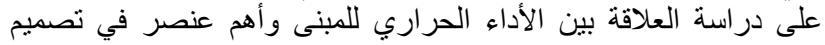

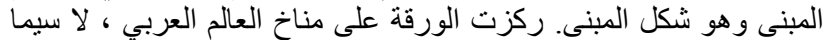

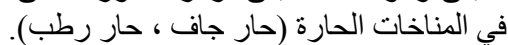

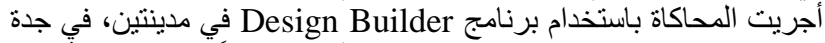

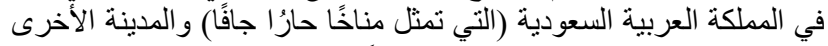

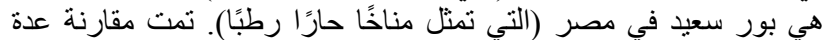

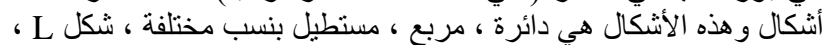

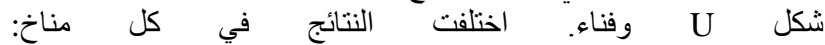

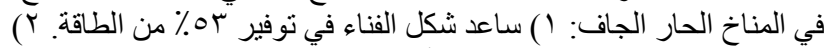

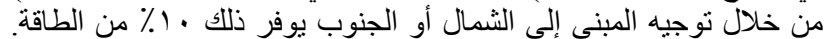

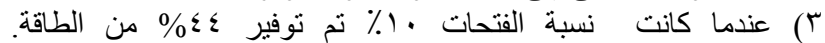

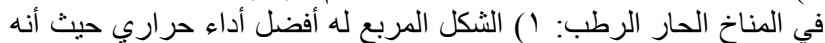

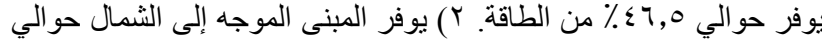

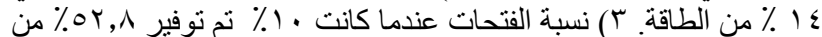

